\title{
Biologia de Paralonchurus brasiliensis (Steindachner) (Teleostei, Sciaenidae) no litoral sul do Estado do Paraná, Brasil ${ }^{1}$
}

\author{
Maurício de C. Robert 2, 3; Maria A. Michels-Souza ${ }^{2,4}$ \& Paulo de T. Chaves ${ }^{2,5}$
}

\author{
${ }^{1}$ Contribuição número 1692 do Departamento de Zoologia, Universidade Federal do Paraná. \\ 2 Programa de Pós-Graduação em Zoologia, Departamento de Zoologia, Universidade Federal do Paraná. Caixa Postal \\ 19020, 81531-980 Curitiba, Paraná, Brasil. \\ ${ }^{3}$ Autor-correspondente. Bolsista CAPES. E-mail: mauriciorobert@bol.com.br \\ ${ }^{4}$ Bolsista CNPq. E-mail: lagunense@hotmail.com \\ ${ }^{5}$ Bolsista Produtividade em Pesquisa CNPq. E-mail: ptchaves@ufpr.br
}

\begin{abstract}
Biology of Paralonchurus brasiliensis (Steindachner) (Teleostei, Sciaenidae) in Paraná coast, Brazil. The populational structure, reproduction and feeding features of banded croaker in southern coast of Paraná State are presented. Samplings were performed through bottom trawl from March 1999 to January 2000 at depths 10 and $15 \mathrm{~m}$. Paralonchurus brasiliensis is more abundant during spring, when the youngest individuals, smaller than $93 \mathrm{~mm}$, are recruited. The relation weight/length for grouped sexes is $\mathrm{TW}(\mathrm{g})=2.74 \mathrm{E}^{-6} \mathrm{TL}(\mathrm{mm})^{3.22}(\mathrm{n}$ $=659 ; \mathrm{R}^{2}=0.99$ ). Gonadal maturation is recorded since the length class $130-165 \mathrm{~mm}$ and the average length of the first maturation (grouped sexes) is estimated in $175 \mathrm{~mm}$. Sand worms (Polychaeta) are the feeding item more usual for the all size classes and seasons, followed by crustacean and fishes. Species reproductive period extends from autumn (start maturation) to summer (end the spawning). After spring, youngs probably leave the area 10 $\mathrm{m}$ of depth. The prohibition of the shrimp bottom trawl in this depth during the spring and the summer must be efficient to reduce $P$. brasiliensis by-catch, today composed by recruits or spawning proximity individuals. KEY WORDS. Banded croaker; by-catch; feeding; recruitment; spawning.
\end{abstract}

RESUMO. Apresentam-se atributos de estrutura populacional, reprodução e alimentação de Paralonchurus brasiliensis no litoral Sul do Estado do Paraná. As coletas foram realizadas com rede de arrasto de fundo, de março de 1999 a janeiro de 2000, sobre as isóbatas 10 e 15 m. Os indivíduos são mais abundantes durante a primavera, época de recrutamento dos jovens menores que $93 \mathrm{~mm}$. A relação peso/comprimento para sexos grupados é PT(g) = $2,74 \mathrm{E}^{-6} \cdot \mathrm{CT}(\mathrm{mm})^{3,22}\left(\mathrm{n}=659 ; \mathrm{R}^{2}=0,99\right)$. Maturação gonadal é registrada a partir da classe de comprimento 130 $165 \mathrm{~mm}$, e o comprimento médio de primeira maturação - sexos grupados - é estimado em 175 mm. Poliquetas são o item alimentar mais freqüente em todas as classes de tamanho e estações do ano, seguidos de crustáceos e peixes. Conclui-se que o período reprodutivo da espécie estende-se do outono (início da maturação) ao verão (final da desova). Após a primavera, os jovens provavelmente saem da área de profundidade $10 \mathrm{~m}$. A interdição do arrasto camaroneiro nesta profundidade durante primavera e verão seria eficiente para reduzir o by-catch de P. brasiliensis, hoje composto por indivíduos recrutas ou em proximidade de desova.

PALAVRAS-CHAVE. Alimentação; by-catch; desova; maria-luísa; recrutamento.

No sul do Brasil, Paralonchurus brasiliensis (Steindachner, 1875) - a maria-luísa - é abundante na zona litorânea em profundidades até 20 m (VAzzoler 1975, Haimovici et al. 1996). Com base em análises de caracteres merísticos e morfométricos (VARGAS 1976), dois grandes conjuntos populacionais foram reconhecidos: um ao norte de 29오 e outro ao sul. PAIVA FILHO \& ZANI-TEIXEIRA (1980), utilizando caracteres distintivos entre ambos e seus respectivos índices de densidade relativa, constataram variações sazonais e latitudinais de sobreposição espacial, entre $22 \circ 5$ e 29 오. A biologia reprodutiva e a estrutura popula- cional da espécie nessas áreas foram abordadas em numerosos trabalhos, dentre os quais Paiva-Filho \& Rossi (1980), GIANNINI \& Paiva-Filho (1990), Coelho et al. (1993), Cunningham \& DinizFilho (1995) e LeWIS \& Fontoura (2005).

Exemplares de maria-luísa são de ocorrência comum nas capturas do arrasto camaroneiro, uma das duas modalidades pesqueiras - juntamente à pesca de emalhe - mais praticadas no litoral do Paraná (ANDRIGUetro-FILHo 2002). Em prospecção realizada ao longo de dez meses (CHAVEs et al. 2003), indivíduos da espécie estiveram presentes em $100 \%$ dos arrastos realizados na 
profundidade $10 \mathrm{~m}$, e em $50 \%$ daqueles realizados em $15 \mathrm{~m}$. Todavia, seu baixo valor comercial gera um considerável descarte a bordo (HaIMOVICI et al. 1996). O período de defeso para o arrasto, fixado anualmente pelo IBAMA (março-junho até 2005, outubro-dezembro em 2006), valoriza os atributos do recurso-alvo os camarões, e ignora o ciclo de vida dos peixes acompanhantes. O presentetrabal ho descreve atributos deestrutura populacional, reprodução e alimentação de $\mathrm{P}$. brasiliensis na no litoral sul do Paraná, gerando subsídio para a legislação de pesca na região.

\section{MATERIAL E MÉTODOS}

As coletas foram realizadas entre março de 1999 e janeiro de 2000, constando de uma campanha ao mês (exceto setembro - zero - e junho - duas), na Plataforma Continental do Estado do Paraná, entre 2546'S e 2550'S, ao norte da barra da Baía de Guaratuba. Seis pontos foram amostrados: três sobre a isóbata de 15 m, numa trajetória coincidente com a linha imaginária que liga as Ilhas de Itacolomis e Currais; e três sobre a isóbata de $10 \mathrm{~m}$ (Fig. 1). Utilizou-se rede de arrasto de fundo com portas, com abertura de boca próxima a $8 \mathrm{~m}$ e malha de $25 \mathrm{~mm}$ entre nós opostos no ensacador, com esforço contínuo de 10 minutos em cada ponto.

Após as coletas os peixes foram transferidos ao laboratório para biometria (contagem de exemplares, medida do comprimento total - CT - em milímetros e pesagem - PT - em gramas). Seis classes de tamanho com intervalo homogêneo foram definidas empiricamente, para tal considerando a amplitude dos comprimentos e o enquadramento dos valores em função do número de classes escolhido. Conforme Arango (2001), esse procedimento é recomendável para evitar a escolha de um número excessivo de classes, imposta pelo uso de fórmulas que apenas levam em consideração o tamanho da amostra, e que geram classes que em seus intervalos não contêm qualquer valor.

As gônadas foram retiradas e aval iadas macroscopicamente quanto ao sexo e estádio de maturação (VAZzoler 1996): “A" imaturo, "B" em maturação, " $C$ " maduro e "D" desovado ou espermiado. O comprimento médio de primeira maturação para sexos grupados foi estimado conforme VAZzOLER (1996), a partir da distribuição da freqüência percentual de adultos (indivíduos em estádio B, C ou D): segundo a classe de comprimento, traça-se manualmente uma curva do tipo sigmóide, cuja inflexão (50\% de adultos) corresponde ao comprimento médio de primeira maturação. Na distribuição sazonal da freqüência dos estádios de maturação, independentemente do sexo, consideraram-se apenas as classes que incluíam indivíduos com comprimento equival ente àquele médio de primeira maturação, ou maior. As gônadas foram pesadas (PG, em gramas) e, dos exemplares cujo tamanho era igual ou maior que os da classe onde se situou o comprimento médio de primeira maturação, calculou-se - para sexos separados - a Relação Gonadossomática (RGS = 100.PG/PT). A distribuição dos valores de RGS foi utilizada como indicador complementar do processo de maturação.

Os estômagos foram fixados em formol 4\% para identifi-

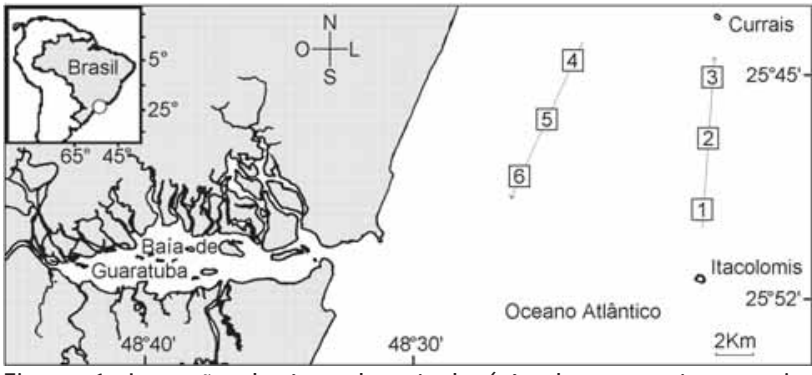

Figura 1. Inserção da área de estudo (círculo no canto superior esquerdo) na Plataforma Continental do sul do Estado do Paraná. Pontos: 1, 2 e 3 (isóbata de 15 m); 4, 5 e 6 (isóbata de 10 m).

cação e quantificação de seu conteúdo. Os dados foram tratados pelo método de Freqüência de Ocorrência: porcentagem de indivíduos em que cada item ocorreu, relativa ao total de indivíduos examinados e cujo estômago não estava vazio.

Os dados de abundância e comprimento de indivíduos, de freqüência dos estádios de maturação, de RGS e de conteúdo estomacal foram analisados sazonalmente. Para tal, considerou-se verão o período de janeiro a março; outono, de abril a junho; inverno, de julho a setembro; e primavera, de outubro a dezembro. Os dados foram ponderados, visto que verão e inverno contaram com apenas duas campanhas (12 amostras), enquanto outono com quatro (24 amostras). Comparações de freqüências absolutas das classes de comprimento e dos estádios de maturação entre as estações do ano foram realizadas através dos testes $\chi^{2}$ com correção de continuidade (SIEGEL 1975). Para não se perder o efeito de ordem nestas comparações, consideraram-se duas categorias (1 grau de liberdade): a categoria de interesse nas comparações e a soma das categorias restantes. A decisão de escolha de hipótese para esses testes, bem como para os demais, sempre se deu em $\alpha=0,05$. Para a escolha do método estatístico adequado nas comparações de médias de abundância e de RGS entre as estações do ano foram realizados os testes de normalidade de Shapiro-Wilk e de homogeneidade de variâncias de Levene (ZAR 1999, ArAngo 2001). Como os dados não atendiam os pressupostos de normalidade e/ou homocedasticidade, as comparações entre médias apenas foram realizadas com o teste Kruskal-Wall is (SIEGEL 1975). Em tendo havido diferenças significativas, pós-comparações foram realizadas com o teste de Nemenyi para determinação de relação de grandeza entre as médias (ZAR 1999).

\section{RESULTADOS}

As capturas de Paralonchurus brasiliensis foram maiores cinco vezes ou mais - na isóbata de $10 \mathrm{~m}$ que na de $15 \mathrm{~m}$. Nesta, entre os 21 exemplares coletados apenas um não excedia 165 $\mathrm{mm}$. A $10 \mathrm{~m}$ o rendimento médio de captura diferiu significativamente entre as estações do ano (Kruskal-Wallis: $\mathrm{H}=11,63 ; \mathrm{p}=$ 0,0088; $n=30$ ) (Fig. 2). Comparações a posteriori indicaram maior rendimento médio de captura durante a primavera $(58,9$ in-

Revista Brasileira de Zoologia 24 (1): 191-198, março 2007 


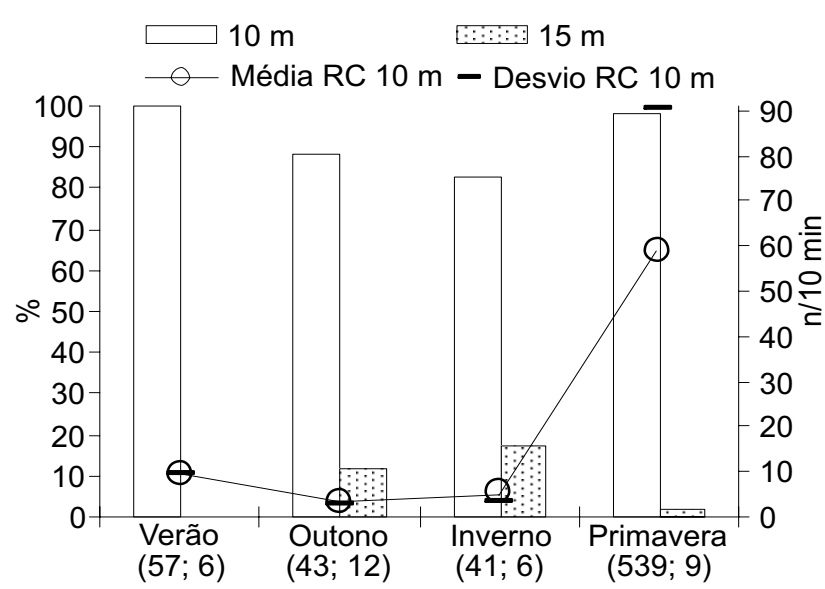

Figura 2. Distribuição relativa do número de indivíduos de $P$. brasiliensis em cada área de coleta (10 m e 15 m), segundo a estação do ano. Parênteses: exemplares capturados e número de amostras por estação, ambas as áreas somadas. A linha contínua indica o rendimento de captura $(\mathrm{RC})$ médio na área referente à isóbata de 10 m (número de exemplares capturados em 10 minutos) e os traços, os respectivos desvios-padrão.

divíduos/10 min), e menor durante o outono (3,4 indivíduos/ $10 \mathrm{~min}$ ) (Tab. I). O comprimento total dos exemplares a $10 \mathrm{~m}$ variou de 22 a 237 mm (Fig. 3). Comparações sazonais da freqüência de indivíduos de uma mesma classe de tamanho indicaram que o recrutamento é mais intenso durante a primavera, estação em que exemplares das classes $22-57 \mathrm{~mm}$ e $58-93 \mathrm{~mm}$ foram mais freqüentes; exemplares da classe 130-165 mm, por sua vez, foram mais freqüentes durante o verão e o outono; e exemplares das classes 166-201 mm e 202-237 mm, durante o verão, o outono e o inverno (Tab. II e Fig. 3).

Tabela I. Resultados das comparações a posteriori entre as médias de Rendimento de Captura de P. brasiliensis referentes às estações do ano, através do teste de Nemenyi. $\left(^{*}\right)$ Indica a presença de diferença significativa em $\alpha=0,05$, (n) número de amostras de ambas as estações comparadas, (q) parâmetro calculado.

\begin{tabular}{llcc}
\hline \multicolumn{1}{c}{ Comparações } & $\mathrm{N}$ & $\mathrm{q}$ & $\mathrm{p}$ \\
\hline Verão/outono & 15 & 1,19 & $>0,500$ \\
Verão/inverno & 12 & 0,05 & $>0,500$ \\
Verão/primavera & 15 & 1,82 & $>0,200$ \\
Outono/inverno & 15 & 1,13 & $>0,500$ \\
Outono/primavera & 18 & 3,36 & $<0,005^{*}$ \\
Inverno/primavera & 15 & 1,87 & $>0,200$ \\
\hline
\end{tabular}

A relação peso/comprimento para sexos grupados, obtida a partir de 659 exemplares, foi PT $(\mathrm{g})=2,74 \mathrm{E}^{-6}$. CT $(\mathrm{mm})^{3,22}$ $\left(\mathrm{R}^{2}=0,99\right)$ (Fig. 4).

O comprimento médio de primeira maturação para sexos

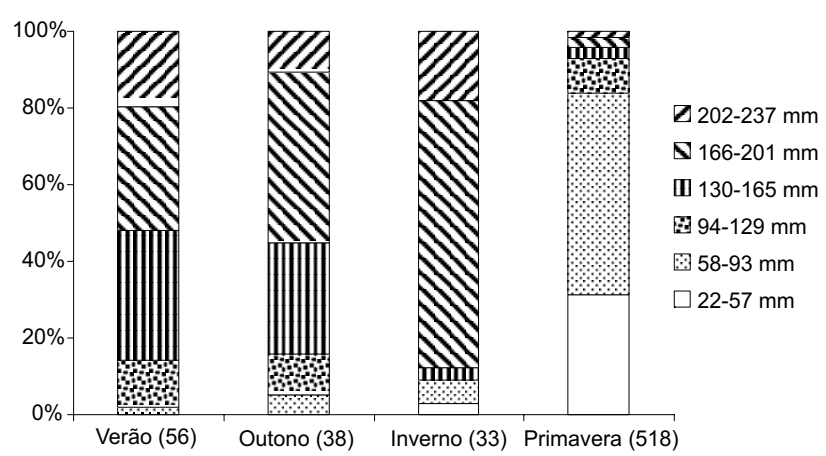

Figura 3. Distribuição das freqüências relativas das classes de comprimento total de P. brasiliensis na isóbata de $10 \mathrm{~m}$, segundo a estação do ano. Parênteses: número de indivíduos.

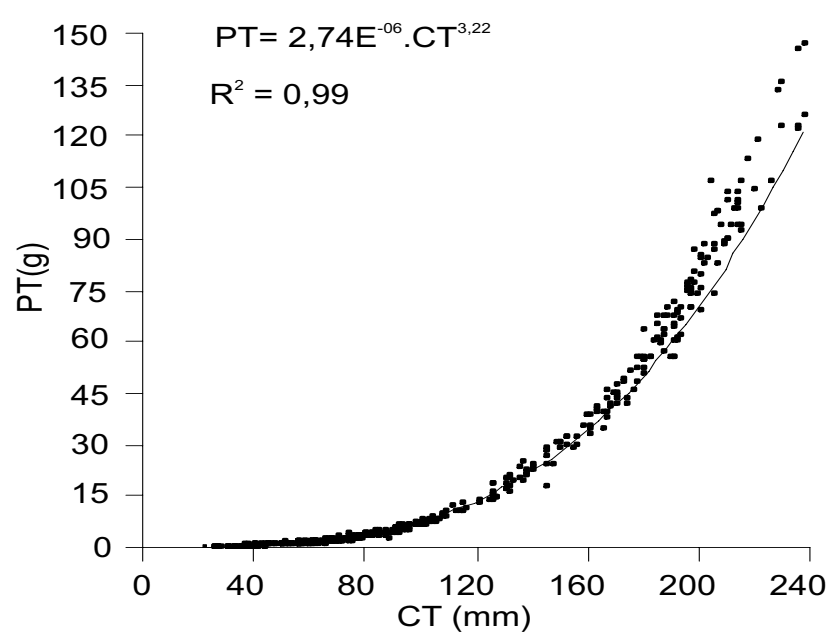

Figura 4. Relação peso (PT)/comprimento (CT) a partir de 659 exemplares de $\mathrm{P}$. brasiliensis, sexos grupados.

grupados foi estimado em $175 \mathrm{~mm}$ (Fig. 5). Indivíduos em maturação de ambos os sexos, e tanto a $10 \mathrm{~m}$ como a $15 \mathrm{~m}$, foram registrados apenas a partir da classe $130-165 \mathrm{~mm}$, enquanto maduros ou desovados/espermiados, da classe 166-201 mm. Para análise da distribuição sazonal da freqüência dos estádios de maturação, independentementedo sexo, consideraram-seas duas classes de maior tamanho (a partir de $166 \mathrm{~mm}$ ), por incluírem os indivíduos com comprimento equivalente ao médio do de primeira maturação, ou maior (Fig. 5). Comparações das freqüências de exemplares em um mesmo estádio de maturação entre as estações do ano revelaram diferenças significativas para exemplares em maturação (mais freqüentes durante o outono e o inverno) e desovados/espermiados (mais freqüentes durante o verão) (Tab. III e Fig. 6). Os valores médios de RGS diferiram significativamente entreas estações do ano, tanto em fêmeas (KruskalWallis: $\mathrm{H}=19,35 ; \mathrm{p}=0,0002 ; \mathrm{n}=65)$, quanto em machos (Kruskal-Wallis: $\mathrm{H}=12,68 ; \mathrm{p}=0,0054 ; \mathrm{n}=49$ ). Comparações a 

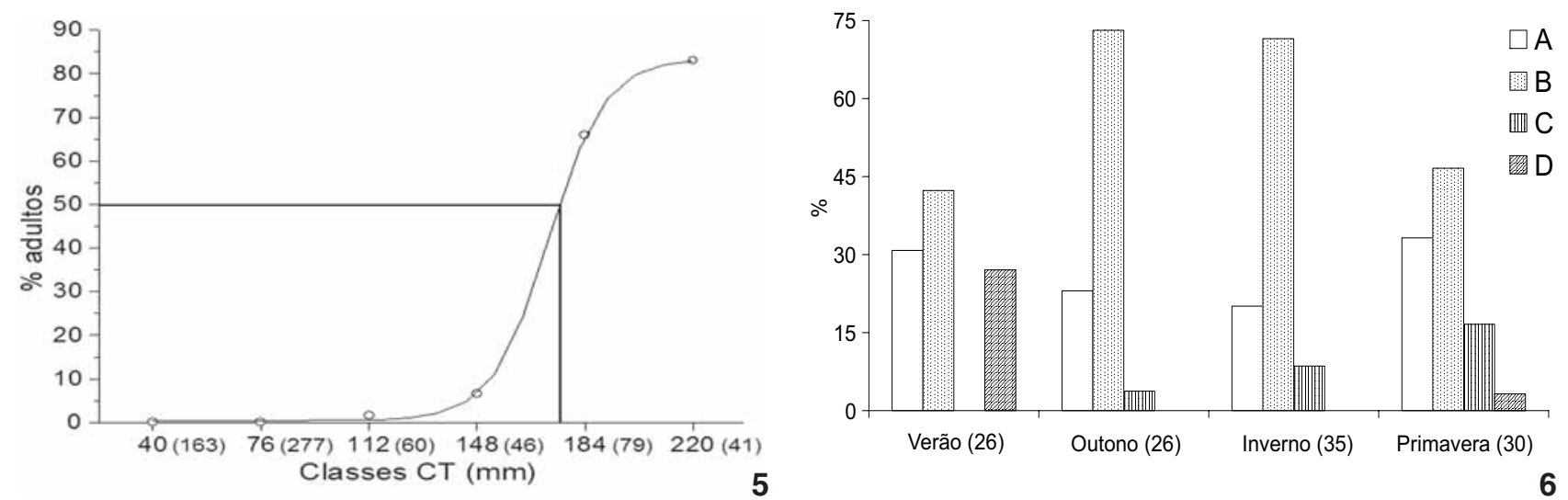

Figuras 5-6. Paralonchurus brasiliensis. (5) Distribuição da freqüência percentual de exemplares adultos, sexos grupados, segundo as classes de comprimento total (CT, ponto médio de cada classe), e estimativa do tamanho médio de primeira maturação (linha vertical). (6) Freqüência relativa dos estádios de maturação gonadal dos indivíduos maiores que $165 \mathrm{~mm}$, para os sexos grupados, segundo a estação do ano. (A) imaturo ou repouso, (B) em maturação, (C) maduro, (D) desovado ou espermiado. Parênteses: número de indivíduos.

Tabela II. Resultados das comparações das freqüências absolutas das classes de comprimento total, a classe em questão e as demais classes conjugadas, entre as estações do ano, através do teste $\chi^{2}$ de contingência com correção de continuidade. $\left(\chi^{2}\right) \chi^{2}$ calculado, $(p)$ probabilidade para $\mathrm{gl}=1$, (n) soma das freqüências absolutas dos indivíduos de ambas as estações comparadas, (-) impossível avaliação, devido a uma respectiva classe possuir freqüência nula em ambas as estações comparadas, $(*)$ diferença significativa em $\alpha=0,05$.

\begin{tabular}{|c|c|c|c|c|c|c|c|}
\hline \multirow{2}{*}{ Classes } & & \multicolumn{6}{|c|}{ Comparações } \\
\hline & & Verão/outono & Verão/inverno & Verão/primavera & Outono/inverno & Outono/primavera & Inverno/primavera \\
\hline \multirow[t]{2}{*}{$\begin{array}{l}22-57 \mathrm{~mm} \text { e } \\
\text { outras classes }\end{array}$} & $\chi^{2}$ & - & 0,070 & 22,330 & 0,010 & 14,910 & 10,250 \\
\hline & $p$ & - & 0,788 & $0,000 *$ & 0,943 & $0,000 *$ & $0,001 *$ \\
\hline \multirow[t]{2}{*}{$\begin{array}{l}58-93 \mathrm{~mm} \text { e } \\
\text { outras classes }\end{array}$} & $\chi^{2}$ & 0,120 & 0,220 & 50,120 & 0,140 & 29,760 & 24,950 \\
\hline & $p$ & 0,731 & 0,637 & $0,000 *$ & 0,711 & $0,000 *$ & $0,000 *$ \\
\hline \multirow[t]{2}{*}{$\begin{array}{l}94-129 \mathrm{~mm} \text { e } \\
\text { outras classes }\end{array}$} & $\chi^{2}$ & 0,000 & 2,920 & 0,290 & 1,970 & 0,000 & 2,290 \\
\hline & $p$ & 0,972 & 0,088 & 0,588 & 0,161 & 0,975 & 0,131 \\
\hline \multirow[t]{2}{*}{$\begin{array}{l}130-165 \mathrm{~mm} \text { e } \\
\text { outras classes }\end{array}$} & $\chi^{2}$ & 0,080 & 9,670 & 81,860 & 6,700 & 48,220 & 0,240 \\
\hline & $\mathrm{p}$ & 0,777 & $0,002 *$ & $0,000 *$ & $0,010 *$ & $0,000 *$ & 0,624 \\
\hline \multirow[t]{2}{*}{$\begin{array}{l}166-201 \mathrm{~mm} \text { e } \\
\text { outras classes }\end{array}$} & $\chi^{2}$ & 1,040 & 10,320 & 81,160 & 3,520 & 115,540 & 218,46 \\
\hline & $\mathrm{p}$ & 0,307 & $0,001^{*}$ & $0,000 *$ & 0,061 & $0,000 *$ & $0,000 *$ \\
\hline \multirow[t]{3}{*}{$\begin{array}{l}202-237 \mathrm{~mm} \text { e } \\
\text { outras classes }\end{array}$} & $\chi^{2}$ & 0,810 & 0,010 & 46,220 & 0,340 & 9,610 & 28,290 \\
\hline & $p$ & 0,370 & 0,913 & $0,000 *$ & 0,560 & $0,002 *$ & $0,000 *$ \\
\hline & $\mathrm{n}$ & 94 & 89 & 574 & 71 & 556 & 551 \\
\hline
\end{tabular}

posteriori revelaram para ambos os sexos valores médios de RGS maiores durante o inverno (fêmeas e machos, respectivamente: 3,03 e 0,41 ) e a primavera $(2,28$ e 0,35$)$, e menores, durante o verão $(0,48$ e 0,20$)$ (Tab. IV e Fig. 7).

Poliquetas foram o item alimentar mais freqüente em todas as classes de tamanho e estações do ano, seguido dos itens "outros crustáceos" e peixes. Observou-se que com o crescimento novos itens adicionam-se à dieta, destacando-se ofiuróides, misidáceos, bivalves e - exclusivos da classe de maior tamanho gastrópodes (Fig. 8). Alguns itens são de ocorrência restrita na dieta: material vegetal, cumáceos e equinodermos (em duas estações), ou diatomáceas, gastrópodes e isópodes (numa estação). 

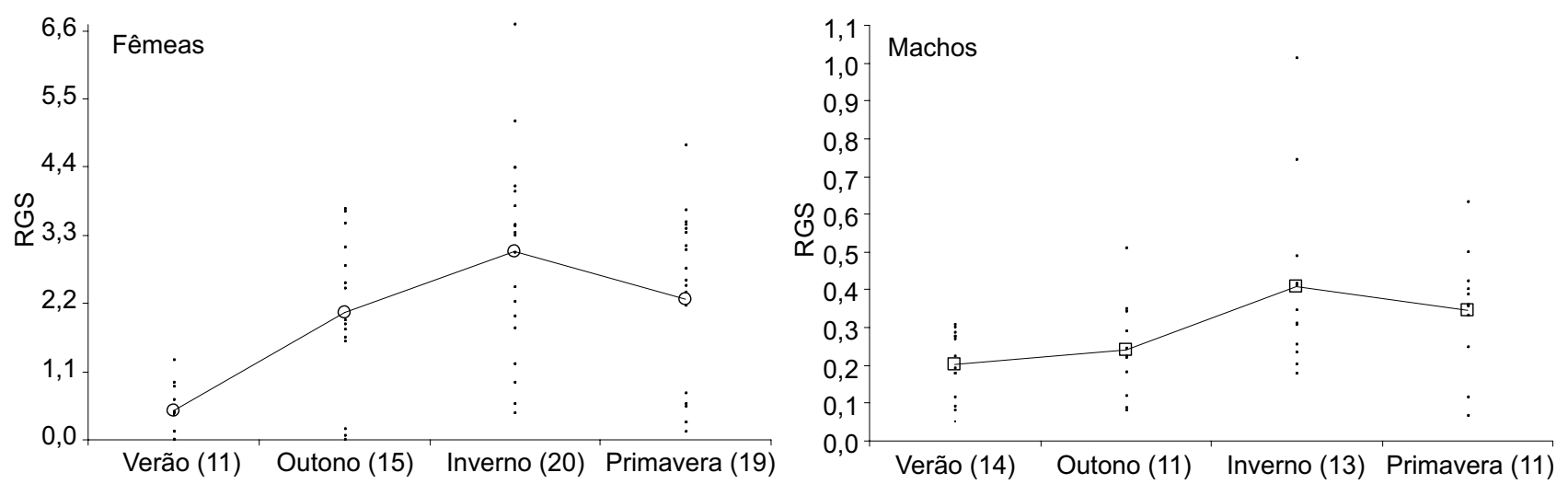

Figura 7. Distribuição dos valores individuais e médios (linha contínua) de Relação Gonadossomática (RGS) de P. brasiliensis maiores que 165 mm, fêmeas e machos, segundo a época do ano. Parênteses: número de indivíduos.

Tabela III. Resultados das comparações das freqüências absolutas dos estádios de maturação gonadal, o estádio em questão (A, B, C ou D) e os demais estádios conjugados, entre as estações do ano, através do teste $x^{2}$ de contingência com correção de continuidade. ( $\chi^{2}$ ) $\chi^{2}$ calculado, (p) probabilidade para $\mathrm{gl}=1$, (n) soma das freqüências absolutas dos indivíduos de ambas as estações comparadas, (-) impossível avaliação, devido ao estádio possuir freqüência nula em ambas as estações comparadas, (*) diferença significativa em $\alpha=0,05$.

\begin{tabular}{|c|c|c|c|c|c|c|c|}
\hline \multirow{2}{*}{ Estádios } & & \multicolumn{6}{|c|}{ Comparações } \\
\hline & & Verão/outono & Verão/inverno & Verão/primavera & Outono/inverno & Outono/primavera & Inverno/primavera \\
\hline \multirow[t]{2}{*}{$A$ e $(B+C+D)$} & $x^{2}$ & 0,100 & 0,440 & 0,010 & 0,000 & 0,300 & 0,880 \\
\hline & $\mathrm{p}$ & 0,755 & 0,506 & 0,935 & 0,979 & 0,582 & 0,349 \\
\hline \multirow[t]{2}{*}{$B$ e $(A+C+D)$} & $\chi^{2}$ & 3,860 & 4,100 & 0,000 & 0,020 & 3,000 & 3,160 \\
\hline & $\mathrm{p}$ & $0,049 *$ & $0,043^{*}$ & 0,954 & 0,883 & 0,083 & 0,076 \\
\hline \multirow[t]{2}{*}{$C$ e $(A+B+D)$} & $\chi^{2}$ & 0,000 & 0,870 & 2,930 & 0,050 & 1,240 & 0,370 \\
\hline & $\mathrm{p}$ & 1,000 & 0,351 & 0,087 & 0,830 & 0,265 & 0,541 \\
\hline \multirow[t]{3}{*}{$D$ e $(A+B+C)$} & $\chi^{2}$ & 5,940 & 8,160 & 4,550 & - & 0,010 & 0,010 \\
\hline & $\mathrm{p}$ & $0,015^{*}$ & $0,004 *$ & $0,033 *$ & - & 0,942 & 0,938 \\
\hline & $\mathrm{n}$ & 52 & 61 & 56 & 61 & 56 & 65 \\
\hline
\end{tabular}

\section{DISCUSSÃO}

Na região estudada Paralonchurus brasiliensis é mais abundante na mesma época - a primavera - em que aumenta a ocorrência de indivíduos menores que $94 \mathrm{~mm}$. Possivelmente isso reflete o recrutamento de jovens, visto que o tamanho dos indivíduos é pequeno, inferior a 55\% do comprimento médio de primeira maturação. Este, aqui calculado em $175 \mathrm{~mm}$ para sexos grupados, é próximo ao registrado para a população da espécie distribuída ao norte de 29ㅇ - 180 mm em fêmeas e 170 $\mathrm{mm}$ em machos (Paiva Filho et al. 1976a), e maior que o da população distribuída ao sul - $148 \mathrm{~mm}$ em fêmeas e $150 \mathrm{~mm}$ em machos (Paiva Filho et al. 1976b). Porém, o comprimento médio de primeira maturação estimado por outros trabal hos, realizados tanto ao norte como ao sul de 29ㅇ, foi menor que o registrado no presente estudo: $145 \mathrm{~mm}$, sexos grupados, entre 2329'S e 2333'S (Cunningham \& Diniz-FILHo 1995); $150 \mathrm{~mm}$ em fêmeas e $148 \mathrm{~mm}$ em machos, entre 2640'Se 26047'S (Bran-
Tabela IV. Resultados das comparações a posteriori entre as médias de Relação Gonadossomática referentes às estações do ano, através do teste de Nemenyi. (*) Diferença significativa em $\alpha=$ 0,05, (n) número de indivíduos de ambas as estações comparadas, (q) parâmetro calculado.

\begin{tabular}{lcccccc}
\hline \multirow{2}{*}{ Comparações } & \multicolumn{3}{c}{ Fêmeas } & \multicolumn{3}{c}{ Machos } \\
\cline { 2 - 7 } & $\mathrm{n}$ & $\mathrm{q}$ & $\mathrm{p}$ & $\mathrm{n}$ & $\mathrm{q}$ & $\mathrm{p}$ \\
\hline Verão/outono & 26 & 2,55 & $>0,05$ & 25 & 0,72 & $>0,50$ \\
Verão/inverno & 31 & 4,36 & $<0,001^{*}$ & 27 & 3,02 & $<0,02^{*}$ \\
Verão/primavera & 30 & 3,15 & $<0,01^{*}$ & 25 & 2,66 & $<0,05^{*}$ \\
Outono/inverno & 35 & 1,83 & $>0,20$ & 24 & 2,13 & $>0,10$ \\
Outono/primavera & 34 & 0,53 & $>0,50$ & 22 & 1,84 & $>0,20$ \\
Inverno/primavera & 39 & 1,38 & $>0,50$ & 24 & 0,22 & $>0,50$ \\
\hline
\end{tabular}

co et al. 2005); e 154 mm em fêmeas em 3008'S (LewIs \& Fontoura 2005). As diferenças podem estar associadas tanto a procedimentos metodológicos como à ocorrência, apontada por 

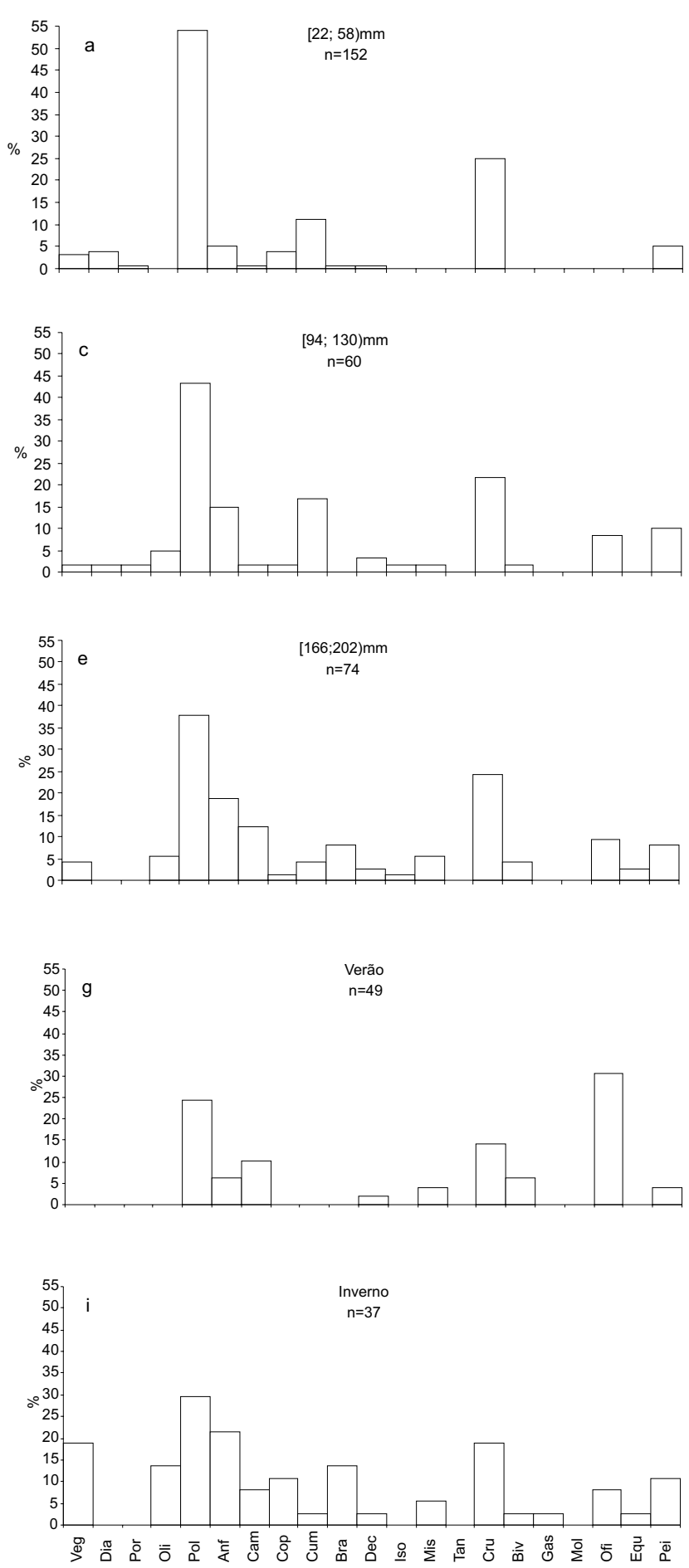
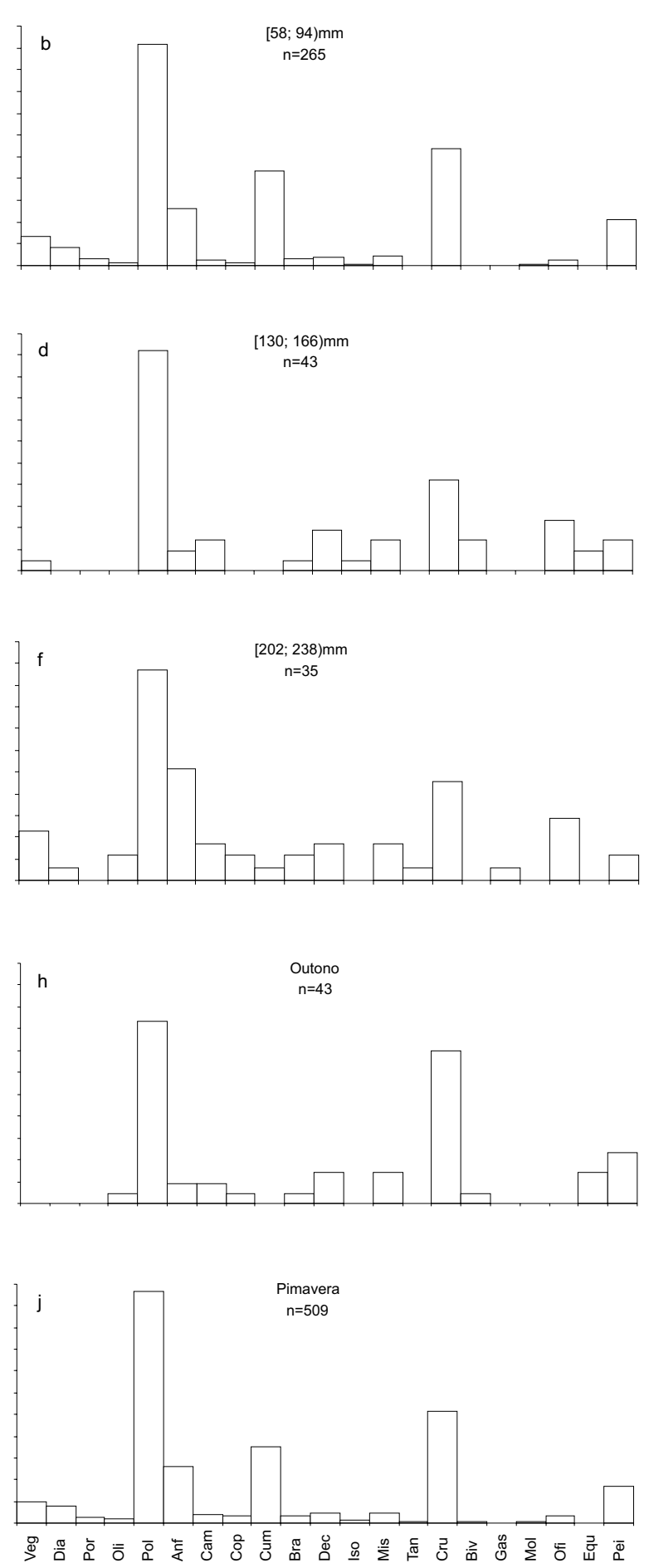

Figura 8. Distribuição dos valores de Freqüência de Ocorrência dos itens alimentares de P. brasiliensis, segundo a classe de comprimento (A a F) e época do ano (G a J). (Veg) Material vegetal, (Dia) diatomáceas, (Por) poríferos, (Oli) oligoquetas, (Pol) poliquetas, (Anf) anfípodes, (Cam) camarões, (Cop) copépodes, (Cum) cumáceos, (Bra) decápodes braquiúros, (Dec) outros decápodes, (Iso) isópodes, (Mis) misidáceos, (Tan) tanaidáceos, (Cru) outros crustáceos, (Biv) bivalves, (Gas) gastrópodes, (Mol) moluscos, (Ofi) ofiuróides, (Equ) outros equinodermos, (Pei) peixes, (n) número de estômagos analisados. 
Paiva Filho \& Zani-Teixeira (1980), de sobreposição espacial entre os dois grandes conjuntos populacionais. A idade média de primeira maturação da espécie foi estimada por BRAGA (1990), no litoral de São Paulo, em quatro anos.

A sel etividade da arte de pesca utilizada, compreendendo rede com pequena abertura de malha e operando no fundo, certamente contribuiu para que o tamanho do maior exemplar coletado $(237 \mathrm{~mm}$ ) fosse muito inferior àquele $(300 \mathrm{~mm})$ noticiado por Menezes \& Figueiredo (1980) como sendo o máximo para a espécie. Defato, indivíduos de até $293 \mathrm{~mm}$ têm sido registrados na região, todavia mediante captura com redes de emal he (observação pessoal dos autores). A arte pode ter influenciado também na ausência de indivíduos menores que $22 \mathrm{~mm}$.

O aumento dos valores de RGS com a proximidade do inverno, bem como de indivíduos maduros na primavera e de desovados/espermiados no verão, indica que o período reprodutivo é longo, estendendo-se do outono (início da maturação) ao verão (final de desova). O período é semelhante àquele registrado para a espécie no litoral de São Paulo (PAIVA Filho \& Rossı 1980, Cunningham \& Dinız-FILho 1995), mas antecipado ao da costa gaúcha - do inverno ao verão (Lewis \& Fontoura 2005). Em a desova ocorrendo da primavera ao verão, é provável que parte dos recrutas da segunda menor classe de tamanho (58-93 mm), registrados na primavera, consista em jovens entrando no primeiro ano de vida. Após a primavera, a diminuição de abundância sinaliza que os jovens saem da área de profundidade $10 \mathrm{~m}$, hipótese reforçada por ao longo do tempo não ter havido progressão modal nas freqüências das classes de comprimento.

A espécie parece não ter uma fase estuarina. Já foi observado que no litoral sul do Paraná os indivíduos não freqüentam regularmente o estuário da Baía de Guaratuba (ChAVES \& Bouchereau 2000). Na Lagoa dos Patos, sul do Brasil, a entrada de jovens foi classificada por Sinque \& Muelbert (1998) e Vieira et al. (1998) como "facultativa" ou "oportunista". Fortalece-se, pois, a hipótese de que os jovens do ano, menores que $94 \mathrm{~mm}$, permanecem até o início da maturação próximos à praia, em profundidade inferior a $10 \mathrm{~m}$, utilizando tal área para crescimento. Quanto aos indivíduos maiores que $129 \mathrm{~mm}$, cujo registro na região foi constante, possivelmente representam o retorno de jovens para a área dos $10 \mathrm{~m}$ e sua fixação aí, onde iniciam a primeira maturação gonadal. Comportamento semelhante foi registrado por Coelho et al. (1993) no litoral de São Paulo.

A dieta da espécie na região corresponde ao relatado por VAzzoler (1975) no litoral do Rio Grande do Sul e por Branco et al. (2005) no litoral de Santa Catarina. A similaridade constatada entre indivíduos de tamanhos diferentes quanto à freqüência de ocorrência dos itens indica que jovens e adultos compartilham recursos semel hantes. A hipótese está sujeita a erro, visto que número, massa ou volume dos itens não foram aqui avaliados. Entretanto, caso efetivamente os recursos sejam utilizados de forma semel hante entre as classes de tamanho, competição trófica entre jovens e adultos pode ser evitada porque - exceto durante a primavera - indivíduos de até $129 \mathrm{~mm}$ são pouco abundantes na região. VAzzoler (1975) observou que no litoral sul do Brasil os Sciaenidae com hábitos alimentares semelhantes têm distribuição disjunta, e associou tal fato a uma redução na possibilidade de competição interespecífica.

Até 2005, a pesca de arrasto de fundo camaroneiro era permitida na região em profundidade $(10 \mathrm{~m}$ ) e época (primavera, verão) em que P. brasiliensis aí recruta e desova. O defeso do arrasto correspondia a meses de outono. Em 2006 ele correspondeu à primavera, portanto a interdição permanece não contemplando integralmente o período reprodutivo da espécie. Frotas de grande-escala (sensu AndRIguetto-FILHo 2002) e industriais, procedentes de Santa Catarina e São Paulo (Chaves \& Robert 2003), praticam suas pescarias de arrasto ou parelha no litoral sul do Paraná em profundidades próximas a 10 m, dessa forma incidindo sobre o estrato populacional aí presente. Igualmente a frota regional, por meio de canoas e pequenos botes, opera nessa profundidade, entretanto com pescarias de emal he tipos fundeio e caceio (Chaves \& Robert 2003, Robert \& Chaves 2006), supostamente menos eficientes para maria-luísa jovens. O presente trabalho não avalia o grau de pressão a que o estoque de P. brasiliensis está exposto no litoral sul do Paraná, para o quê uma investigação específica necessitaria ser realizada. Em região próxima à do presente estudo - Penha, litoral norte Santa Catarina (2640'S-2647'S) - séries históricas de dados de 1996 a 2003 indicam estabilidade no rendimento de captura da espécie (BRANco et al. 2005). Se investigações complementares indicarem necessidade de redução da pressão de pesca sobre a espécie, a interdição do arrasto na profundidade em torno de $10 \mathrm{~m}$, durante a primavera e o verão, será eficiente para reduzir a captura de indivíduos recrutas ou em proximidade de desova. Outros estudos devem considerar, ainda, as áreas mais rasas, onde provavelmente se criam os jovens antes do recrutamento.

\section{AGRADECIMENTOS}

A Rut Schlichting e a Leticia Knechtel Procopiak pelo auxílio na redação do Abstract. Trabalho realizado com recursos CAPES e CNPq.

\section{REFERÊNCIAS BIBLIOGRÁFICAS}

Andriguetto-Filho, J.M. 2002 Sistemas técnicos de pesca no litoral do Paraná: caracterização e tipificação, p. 213-233. In: C. Raynaut; M. Zanoni; P.C. Lana; D. Floriani; A.D.D. Ferreira \& J.M. Andriguetto-Filho (Eds). Desenvolvimento e meio ambiente: em busca da interdisciplinaridade. Pesquisa urbanas e rurais. Curitiba, Editora UFPR, 295p.

Arango, H.G. 2001. Bioestatística teórica e computacional. Rio de Janeiro, Guanabara Koogan, 235p.

BragA, F.M.S. 1990. Estudo da mortalidade de Paralonchurus brasiliensis (Teleostei, Sciaenidae), em área de pesca do camarão-sete-barbas (Xiphopenaeus kroyeri). Boletim do Instituto de Pesca 17: 27-35.

Revista Brasileira de Zoologia 24 (1): 191-198, março 2007 
Branco, J.O.; M.J. Lunardon-Branco \& J.R. Verani. 2005. Aspectos biológicos e pesqueiros de Paralonchurus brasiliensis Steindachner, (Pisces, Sciaenidae), na Armação do Itapocoroy, Penha, Santa Catarina, Brasil. Revista Brasileira de Zoologia 22 (4): 1063-1071.

Chaves, P. \& J.L. Bouchereau. 2000. Use of mangrove habitat for reproductive activity by the fish assemblage in the Guaratuba Bay, Brazil. Oceanologica Acta 23: 273-280.

Chaves, P.T.; G. Cova-Grando \& C. Calluf. 2003. Demersal ichthyofauna a continental shelf region on the south coast of Brazil exposed to shrimp trawl fisheries. Acta Biológica Paranaense 32 (1-4): 69-82.

Chaves, P.T.C \& M.C. Robert. 2003 Embarcações, artes e procedimentos da pesca artesanal no litoral Sul do Estado do Paraná, Brasil. Revista Atlântica 25 (1): 53-59.

Coelho, J.A.P.; R.G. Lopes; E.S. Rodrigues; A. Puzzi \& D.S. Farias. 1993. Aspectos biológicos e pesqueiros do Sciaenidae Paralonchurus brasiliensis (Steindachner, 1875) presente no rejeitado da pesca artesanal dirigida ao camarão-sete-barbas (São Paulo, Brasil). Boletim do Instituto de Pesca 20: 95-101.

Cunningham, P.T.M. \& A.M. Diniz-Filho. 1995. Aspectos da biologia de Paralonchurus brasiliensis - Sciaenidae - no litoral norte de São Paulo, Brasil. Publicação Especial do Instituto Oceanográfico 11: 203-210.

Giannini, R. \& A.M. Paiva-Filho. 1990. Os Sciaenidae (Teleostei: Perciformes) da Baía de Santos (SP), Brasil. Boletim do Instituto Oceanográfico 38 (1): 69-86.

Haimovicl, M.; A.S. Martins \& P.C. Vieira. 1996. Distribuição e abundância de peixes tel eósteos demersais sobre a plataforma continental do sul do Brasil. Revista Brasileira de Biologia 56 (1): 27-50.

Lewis, D.S. \& N. Fontoura. 2005. Maturity and growth of Paralonchurus brasiliensis females in southern Brazil (Teleostei, Perciformes, Sciaenidae). Journal of Applied Ichthyology 21: 94-100.

Menezes, N.A. \& J.L. Figueiredo. 1980. Manual de peixes marinhos do sudeste do Brasil. IV. Teleostei (3). São Paulo, Universidade de São Paulo, Museu de Zoologia, 96p.

Paiva-Filho, A.M. \& L. Rossi. 1980. Estudo sobre a fecundidade e a desova de Paralonchurus brasiliensis (Steindachner, 1875), população SP (Osteichthyes, Sciaenidae). Revista Brasilei- ra de Biologia 40 (2): 241-247.

Paiva-Filho, A.M. \& M.L. Zani-Teixeira. 1980. Estudo da sobreposição espacial das populações de Paralonchurus brasiliensis (Steindachner, 1875) na costa Sudeste-Sul do Brasil entre as

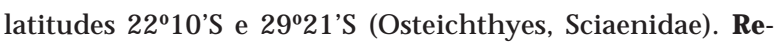
vista Brasileira de Biologia 40 (1): 143-148.

Paiva-Filho, A.M.; A.E.A.M. Vazzoler \& M.L. Zanı. 1976a. Paralonchurus brasiliensis população SP: análise da curva de maturação, primeira maturação e sex-ratio. Suplemento Ciência e Cultura 28 (7): 219-220.

Paiva-Filho, A.M.; A.E.A.M. Vazzoler \& M.L. Zanı. 1976b. ParaIonchurus brasiliensis, população RS: análise da curva de maturação, primeira maturação e sex-ratio. Suplemento Ciência e Cultura 28 (7): 220.

Robert, M.C. \& P.T. Chaves. 2006. Dinâmica da atividade pesqueira artesanal em duas comunidades da região litorânea limítrofe Santa Catarina-Paraná, Brasil. Boletim do Instituto de Pesca 32 (1): 15-23.

SiegEL, S. 1975. Estatística Não-paramétrica para as Ciências do Comportamento. São Paulo, McGraw-Hill, 350p.

Sinque, C. \& J.H. Muelbert. 1998 Ictioplâncton, p. 56-60. In: U. Seeliger; C. Odebrecht \& J.P. Castello (Eds). Os ecossistemas costeiro e marinho do extremo sul do Brasil. Rio Grande, Ecoscientia, 326p.

VARGAS, C.P. 1976. Diferenciação geográfica de Paralonchurus brasiliensis (Steindachner, 1875), entre 2330'S (Ubatuba) e 32-S (Barra do Rio Grande). Suplemento Ciência e Cultura 28 (7): 221.

VAZZOLER, G. 1975. Distribuição da fauna de peixes demersais e ecologia dos Sciaenidae da Plataforma Continental brasileira, entre as latitudes $29^{\circ} 21^{\prime} \mathrm{S}$ (Torres) e $33^{\circ} 41^{\prime} \mathrm{S}$ (Chuí). Boletim do Instituto Oceanográfico 24: 85-169.

VAZZoler, A.E.M. 1996. Biologia da reprodução de peixes teleósteos: teoria e prática. Maringá, EDUEM, SBI, 169p.

Vieira, J.P.; J.P. Castello \& L.E. Pereira. 1998. Ictiofauna, p. 60-68. In: U. Seeliger; C. Odebrecht \& J.P. Castello (Eds). Os ecossistemas costeiro e marinho do extremo sul do Brasil. Rio Grande, Ecoscientia, 326p.

ZAR, J.H. 1999. Biostatistical analysis. New Jersey, PrenticeHall, 663p.

Recebido em 11.VIII.2006; aceito em 06.III.2007.

Revista Brasileira de Zoologia 24 (1): 191-198, março 2007 